\title{
Abuse of Parking Facilities and the Decay of Ikeja Central Business District, Ikeja Local Government Area, Lagos State
}

\author{
${ }^{1}$ Ige J. O; ${ }^{2}$ Adetunji M.A. and ${ }^{3}$ Akinyemi, K. O. \\ ${ }^{1,2,3}$ Department of Urban and Regional Planning, Ladoke Akintola University of Technology, Ogbomoso, Oyo State, Nigeria. \\ Corresponding author E-mail: maadetunji@lautech.edu.ng
}

Submitted on: 02/08/2021

Accepted on: 30/09/2021

\begin{abstract}
Illegal parking has been a topical issue in environmental planning and management, especially in the area of generating early warning systems for preparedness against space abuse. However, the concentration of research effort on accessibility in central business district with unjustified neglect of parking abuse impedes the search for analytical explanations and effective strategies to control spatial challenges. The study examined the types and nature of parking facilities and parking abuse. It also examined causes and effects of the abuse, as well as the response to abuse of the parking facilities in Ikeja Central Business District of Ikeja Local Government Area. Primary and secondary data were used for the study. Primary data were collected through in-depth interview with opinion leaders and questionnaires administered to 106 respondents randomly sampled in the core and periphery of the Central Business District of Ikeja. The data collected were analyzed using descriptive statistics such as frequency counts, percentage and chi-square. Secondary data used were map of the study area and images generated from Google earth. Results showed that there were two types of parking facilities; off-street (destination parking lot) and on-street parking facilities in the area. The nature of parking abuse was highly indiscriminate, and the prevailing type of parking facility abuse in the study area was unauthorized conversion of earmarked parking spaces to commercial trading spots. The effects of the parking abuse were mainly unavailability of parking space and traffic congestion, and the major perpetuators of the abuse were traders. The response of enforcement officials to indiscriminate parking was affirmed to be inefficient by $87.7 \%$ of the respondents. The study concluded that the abuse of parking facility was rampant in the study area.
\end{abstract}

Keywords: CBD, Abuse, Congestion, Parking Facilities, Parking Lot,

\section{Introduction}

Transportation has liberated man and made him more mobile. Its role in daily activities cannot be overemphasized this is because without it, the necessities of life would be difficult to achieve. Despite the important role that transportation plays in daily activities, it has been noted to possess myriads of negative effects (Oyesiku, 2002). Little wonder transport is described as the maker and breaker of cities. Abuse of parking facility is an urban cankerworm and one of the most notable threats to city mobility and transport development. In Nigeria, abuse of parking facility has become a hydra-headed social monster pervading every dimension of human survival and stable life style. One is reminded of parking abuse every city one goes in Nigeria. It is not just the warning signs, and the long line of vehicles parked along the road side that indicate rampant logjam, but the presence, day and night, of traffic law enforcement agents and increased growth of troop movements and other armed guards controlling the traffic. Transportation has been one of the major activities of man's environment. Man's ability to move himself and his materials from one point to another on the earth's surface significantly influences his life and his environment (Ogunsanya, 1986). 
According to Obot and Umoh (2007), in Nigeria, road transportation is the dominant modes of transportation but free movement of vehicles within urban space is one of the most obvious problems, because parking seems to be an overlooked element of transportation development. Venues of activities often generate enormous parking demands, and the difficulty of parking vehicles at desired destinations particularly when located within the central areas of the city constitute a major logjam. Tanimowo and Atolagbe (2006) observe that improvement in the living standards of people as a result of wage increase contributes almost as much as the growth of cities to contemporary urban traffic condition in Nigeria However, Akhuewu (2010) opines that for a city to function as a system, transportation must be efficient and reliable to facilitate, not only intercity movement of people and their activities, but to encourage intracity movements within the city. These movements are from point of origin to the point of destination.

The concept of parking is the act of stopping and disengaging a vehicle and leaving it unoccupied. Parking is an essential component of a transport system, vehicles are parked at convenient locations. Parking convenience affects the ease of reaching destinations and therefore affects overall accessibility (Litman, 2013). Parking is an aspect of transport facilities which need to be catered for and used as management tool to achieve an inclusive and functional circulation system. Every car on the road requires parking space as an origin for next travel or the destination to end a travel, this makes parking management an indispensable aspect of transportation system. (Bekir \& Surhid, 1997). Most vehicular journeys involve parking at both the start and end of each trip. The availability and cost of car parking can influence decisions on the transport mode used, the time and, the choice of destination.

The central business district remains the most important commercial area in a town, with its dominating position as the seat of commercial activities. The central business area is the origin and destination of the biggest vehicular streams as the activities therein demand a lot of loading and offloading of not just human but goods and services. It is there that the traffic problem emanated and is greatest. Therefore, demand for parking spaces and other facilities are high. Inability of the existing situation to survive in equilibrium with the several competing demand has often led to encroachment of parking space by commercial activities causing parking problem and then traffic congestion.

The space required for parking requires can be problematic in any city, but it poses particular problem in Central Business Districts (CBD) due to high traffic generation. A CBD thrives on high density because of its prime advantage over other parts of a metropolitan area and its proximity to the immediate availability of a wide variety of activities. The clustering of museums, theaters, restaurants, and offices is the commodity a downtown can offer and that other areas may not have clusters of such public facilities cannot (Feeney and Bernard, 1989; Brandley,1997). The tremendous number of private vehicles in use due to inadequate public transport facilities jeopardizes the CBD's advantage, because it renders proximity between some land uses unnecessary, and the density that makes the CBD healthy makes it unsuitable for driving (Bottles, 1987; Foygelson, 2002; Jackie and Sculle, 2004). For Central Business District areas, the challenge of the auto age has been to accommodate the automobile enough to maintain their vitality, and not to become paralyzed by congestion (Kafewo, 2016).

Increasing population both within cities and their surrounding areas without adequate planning to improve the living condition of the teeming masses and provide amenities and essential services has been associated with increased facility abuse and poverty, while poverty is being addressed by different governmental initiatives and policies, abuse of facility continues to be demonstrated by occasional increase in the number of law enforcement personnel without proper understanding and analysis of where the various abuse occur with a view to providing the mechanism for controlling and managing them. Past research dissertations on parking focuses mainly on parking patterns, and methods of car parking with 
LAUTECH Journal of Civil and Environmental Studies

Volume 7, Issue 2; September, 2021

extra focus on provision and use of off-street parking facilities, (Olorunfemi, 2013; Osoba,2002). Despite numerous research efforts on parking, there has been few publications intended to analyze the level of abuse these facilities undergo and how it affects the effectiveness of this facilities. The study examined the types of parking facilities and nature of parking abuse. It also examined causes and effects of the abuse, as well as the state of response to abuse of the parking facilities in Ikeja Central Business District of Ikeja Local Government Area. More specifically, if laws affect behavior, does the absence of strict laws against parking abuses affect commuters parking behavior?

\section{Materials and Methods}

\section{The study area}

The study focuses Central Business District (CBD) of Ikeja Local Government Area. The strategic location of Ikeja CBD as a transit point to the nooks and crannies of Lagos and Ogun States makes it prone to traffic logjam and choice for the research. Ikeja Local Government Area is located in the north central part of Lagos state; Geographically, Ikeja LGA approximately stretches between latitudes $6.6018^{\circ}$ and $6.40238^{\circ}$ North and longitudes $3.3515^{\circ}$ and $3.2305^{\circ}$ East with total Land Area $49.92 \mathrm{~km}^{2}$ and Elevation of $-39 \mathrm{~m}$ (128 it). It is bounded on the north by Ogun state and by Kosofe local government on the East and Ifako- Ijaiye Local Government as well as Agege Local Government, Alimosho Local Government on the western side, while it shares boundary with Oshodi- Isolo and Mushin Local Government on its southern boundaries. The Local Government boasts of a population of about 861,300 people by 2015 based on the National Population Census (2006). It also has a density of $17,254 / \mathrm{km}^{2}$ $(44,690 / \mathrm{sqm})$.

\section{Data collection and analysis}

Data for this study were obtained from both primary and secondary sources. The data from primary sources were obtained through questionnaire administration, direct observation of existing situations in the CBD and oral interview conducted on opinion leaders in the CBD. All residents in the CBD constituted the sample frame, and 106 respondents of all residents in the CBD made up the sample size. Multistage sampling procedure was used for data collection. In the first stage, five per thousand $(5 \%)$ of total residents in Ikeja CBD was considered. Secondly, the study area was stratified into core and periphery (area of influence). Thirdly, in each of the classified strata, questionnaires were randomly distributed to respondents based on randomly selected 106 buildings. Then, questionnaires were administered to randomly identified respondents in selected 106 buildings. using a ratio of 2(core): 3 (periphery), based on strata hierarchical selection model, (i.e., the ratio is based on the premise of average dwelling units' distribution pattern among strata (core and periphery)). The total number of questionnaires administered in core and periphery of Ikeja CBD were therefore 64 and 42 respectively. The numbers given to housing units for enumeration area demarcation for 2006 population census by National Population Commission, and a good proportion of newly constructed buildings that were not numbered were updated, and both compiled for the selected area types (core and periphery) in the CBD of Ikeja Local Government Area. From the compiled lists, required 106 housing units were randomly selected in both of the selected area types. One of all persons aged 18 years and above was purposively interviewed in each selected housing units. It is equally noteworthy to mention that there were some cases where housing units selected were empty (either unoccupied or occupants not at home) such housing units were skipped to the nearest unselected housing units. 


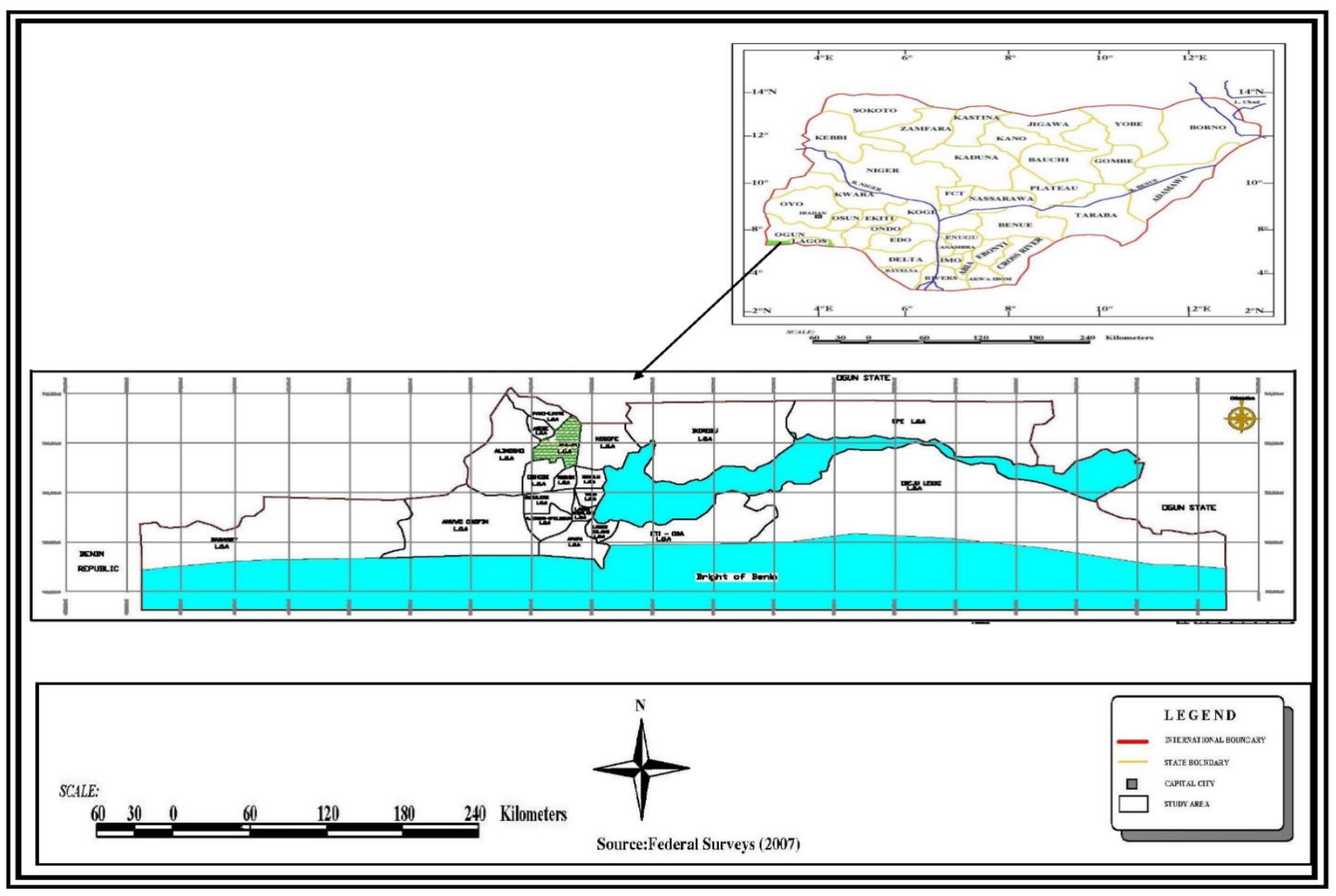

Figure 1: Ikeja in Lagos State

Method of data analysis was mainly descriptive. Descriptive statistics were appropriately used in the analysis of results to present discussions and to depict vividly a summary description of the results. Descriptive analysis adopted includes, the use of frequency counts and percentage. Chi-Square was used to determine level of significant difference between some elements of parking abuse in the Central Business District.

\section{Results and Discussions}

\section{Occupation differential and ease of parking}

As shown in Table 1, more than half of the respondents (81.1\%) affirmed that it was very difficult to find a parking space in the core area of the $\mathrm{CBD}$, with (17.0\%) of the respondents affirming that parking space is neither easy nor difficult, while a minute proportion of (1.9\%) claimed easiness to find a parking space in the core area of the CBD. The difficulty of getting a parking space in the core area of the CBD was attributed to the high percentage of car ownership among the traders and technicians in the CBD and high rate at which the parking space are converted to commercial use by the traders. From the chi-square analysis, as shown in Table 1, the p-value of 0.000 which is less than 0.05 shows that there is significant difference between occupation of respondents and the ease of finding a parking place in the CBD, it shows that occupation of respondents had a significant impact on the ease of getting a parking spot in the study area. 
LAUTECH Journal of Civil and Environmental Studies

Volume 7, Issue 2; September, 2021

Table 1: Relationship between Occupation and Ease of Parking

\begin{tabular}{|c|c|c|c|c|c|}
\hline \multirow{2}{*}{\multicolumn{2}{|c|}{ Residents' Occupation }} & \multicolumn{3}{|c|}{ Ease of finding a parking space in the CBD? } & \multirow{2}{*}{ Total } \\
\hline & & Easy & Normal & Difficult & \\
\hline \multirow[t]{2}{*}{ Civil Servants } & Frequency & 2 & 3 & 10 & 15 \\
\hline & $\%$ & 1.9 & 2.8 & 9.4 & 14.2 \\
\hline Transport & Frequency & 0 & 13 & 2 & 15 \\
\hline Driver & $\%$ & 0.0 & 12.3 & 1.9 & 14.2 \\
\hline \multirow{2}{*}{ Trader } & Frequency & 0 & 0 & 59 & 59 \\
\hline & $\%$ & 0.0 & 0.0 & 55.7 & 55.7 \\
\hline \multirow{2}{*}{ Artisan } & Frequency & 0 & 2 & 15 & 17 \\
\hline & $\&$ & 0.0 & 1.9 & 14.2 & 16.0 \\
\hline \multirow{2}{*}{ Total } & Frequency & 2 & 8 & 86 & 106 \\
\hline & $\%$ & 1.9 & 17.0 & 81.1 & 100 \\
\hline
\end{tabular}

Major perpetuators of the parking facility abuse in the study area

As shown in Table 2 a total of $60.4 \%$ respondents agreed that indiscriminate parking was mostly perpetuated by street traders, shop owners were found to be next by $25.5 \%$ while private individuals constitute $14.1 \%$. Further analysis also revealed that category of vehicles that mostly perpetuated indiscriminate parking in the study area were private cars $(49.1 \%)$ which was closely followed by commercial vehicles $(32.1 \%)$ and bus rapid transit buses (18.8\%). From in-depth interview, it was then observed that street traders who did not have enough resources to get shops due to high cost of rent at the CBD were the ones who mostly engaged in indiscriminate parking in Ikeja core area.

\section{Effects of the parking facility abuse}

Recognizing the effects of the parking facility abuse in the study area was not farfetched as shown in table $3,26.5 \%$ of respondents was of the opinion that the abuse led to breach of public peace and this is due to people's reaction to blockage of thorough fare along driveway. This blockage of thorough fare was known to have severally escalated into full blown clashes between motorists, commercial drivers and traders based on rivalry claims of the right ownership of way. The second leading effect of the facility abuse was the reduction in motorist sight distance $(22.6 \%)$, as a result of several vehicles parking along driveways.

Table 2: Major Perpetuators of the Parking Facility Abuse in the Study Area

\begin{tabular}{lll}
\hline Major perpetuators of the indiscriminate parking & Frequency & Percent \\
\hline Street traders & 64 & 60.4 \\
Shop owners & 27 & 25.5 \\
Private individuals & 15 & 14.1 \\
Total & 106 & 100.0 \\
Type of vehicles perpetuates the abuse & Frequency & Percent \\
Private cars & 52 & 49.1 \\
Commercial buses & 34 & 32.1 \\
Taxis & 0 & 0 \\
Motorcycles & 0 & 0 \\
BRT buses & 20 & 18.8 \\
Total & 106 & 100.0 \\
\hline
\end{tabular}

Source: Authors' Fieldwork, (2019) 
This might lead to narrow road which in turn lead to vehicular-pedestrian conflicts and often result into accidents. Also, $21.7 \%$ of respondents were of the opinion that the abuse of the parking facility caused parking congestion in the area which is due to the reduction in parking space. It was affirmed by $16 \%$ of the respondents that the facility abuse caused traffic congestion in the area due to the blockage the right of way. Analysis revealed that half of the respondents (7.5\%) attested that facility abuse lead to harboring of refuse under the parked car, this was a common act among pedestrians who threw rubbish under stationary vehicle, and $5.7 \%$ of the respondents attested that the abuse caused road accidents due to blockage of motorists' sight distance.

Table 3: Effects of the parking facility abuse

\begin{tabular}{lll}
\hline Effect of wrong parking in the CBD & Frequency & Percent \\
\hline Traffic congestion & 17 & 16 \\
Road accidents & 6 & 5.7 \\
Reduction in sight distance & 24 & 22.6 \\
Breach of public peace due to blockage of thoroughfare & 28 & 26.5 \\
Harboring of refuse under the stationary car & 8 & 7.5 \\
Parking congestion & 23 & 21.7 \\
Total & 106 & 100.0 \\
\end{tabular}

Source: Authors' Fieldwork, (2019)

\section{Efficiency of response to the abuse of parking facilities by law enforcement agents}

The Residents were skeptical about activities of law enforcement agents in controlling abuse of parking facilities. As shown in Table 4, the law enforcement officials were identified by $87.7 \%$ of the respondents to be inefficient in discharging their duties despite the presence and increased growth of enforcement officials like LASTMA and Local Government parking enforcement officials who operated within and around the study area to curb indiscriminate parking by enforcing parking fines such as towing of violators vehicles. However, $7.5 \%$ of the respondents claim that the enforcement officers are efficient in discharging their duties, and $(4.7 \%)$ of the respondents are undecided about the level of efficiency of the officers. From this, it can be deduced that enough was not done by the law enforcement agents in bringing to the book the perpetrators of abuse of parking facilities in the area.

Table 4: Efficiency of parking enforcement

\begin{tabular}{lll}
\hline $\begin{array}{l}\text { Please rate the efficiency of parking enforcement officers } \\
\text { in the area? }\end{array}$ & Frequency & Percent \\
\hline Efficient & 8 & 7.5 \\
Inefficient & 93 & 87.7 \\
Undecided & 5 & 4.7 \\
Total & 106 & 100.0 \\
\hline
\end{tabular}

Source: Authors' Fieldwork, 2019

\section{Adequacy and efficiency of enforcement officers}

A cross-tabulation of data from the number of respondents that rated adequacy and efficiency of enforcement personnel in checking indiscriminate parking shows that there was a significant difference between adequacy and efficiency of law enforcement personnel in discharging their duties, this shows that if the number of law enforcement personnel is increased there will be a relative improvement in the efficiency of law enforcement personnel in the CBD. 


\section{Policy oriented remark / planning implication of the study}

Urban planning is a response to series of environmental problems. It therefore makes use of its instrument (development control) to deal with the arising issues according to laid down principles, and to also provide informed decision support for the government in ameliorating societal problems for the purpose of creating a conducive environment for all inhabitants. Amelioration of the abuse of parking facility and the provision of new public parking facility in the CBD of lkeja can be related to Keeble's definition of town planning, the art and science of ordering the use of land and sitting of building and character and communication routes so as to secure the maximum practicable degree of economy conveniences and beauty.

Table 5: Adequacy of Enforcement Personnel and their Efficiency in Parking Monitoring

\begin{tabular}{ccllll}
\hline & & Efficient & Inefficient & Undecided & Total \\
\hline Adequate & Frequency & 0 & 23 & 3 & 26 \\
& $\%$ & 0.0 & 24.7 & 60.0 & 24.5 \\
Inadequate & Frequency & 6 & 70 & 2 & 78 \\
& & 75.0 & 75.3 & 40.0 & 73.6 \\
Undecided & Frequency & 2 & 0 & 0 & 2 \\
& $\%$ & 25.0 & 0.0 & 0.0 & 1.9 \\
\multirow{5}{*}{ Total } & Frequency & 8 & 93 & 5 & 106 \\
& $\%$ & 100.0 & 100.0 & 100.0 & 100.0 \\
\hline \multicolumn{2}{l}{ Source: Authors field work, (2019) } & & \multicolumn{3}{c}{$\mathrm{X}^{2}=29.833 ; \mathrm{DF}=4, \mathrm{p}=0.000$}
\end{tabular}

\section{Conclusion}

Based on findings, the need to a vibrant Central Business District environment that relies on sustainable socio-economic and conducive environment to support the population at micro and macro levels in the area is considered important. Though abuse of parking facility through illegal conversion to commercial use is an abuse use of precious space, and it's against the basic principles of planning, however it can be entirely eradicated through deliberate actions. This study observed that certain human factors such as inefficiencies of the Ikeja district town planning enforcement department and the inefficiencies of the traffic enforcement personnel influenced the abuse of parking facilities and the decay presently witnessed in the study area. Another of such influencing factor is the non-availability of enough parking infrastructures in the CBD. Base on the research findings, the researcher's following recommendations are put forward which is hoped will assist in ameliorating the indiscriminate parking challenges in the CBD with affecting the commercial activities of the traders.

A judicious application of appropriate traffic management measures will help to mitigate some of the ill effects of parking facility abuse. These measures should be of a comprehensive parking policy for the city. The regulatory measures range from waiting restrictions in a street to the comprehensive control over an extended area. The measures should be periodically reviewed and altered, if necessary, the regulatory measures are generally of two types, one where the use of parking space is authorized for certain periods free or for payment and others where parking and vehicular traffic is completely prohibited but which allows parking for picking up or letting down the goods. When controlled puking scheme is planned, the zone boundaries should be delineated and suitable signs are installed. Land use location and allocation within the CBD environs should also be integrated and planned as to efficiently and aesthetically enhance the quality and functionality of the environment. Parking design, construction and operations be re- 


\section{Abuse of Parking Facilities and the Decay of Ikeja Central Business District,}

Ikeja Local Government Area, Lagos State

conceptualized to attract investors, while government create enabling environment, via legislative instruments to ensure adequate investment returns without unduly exploiting beneficiaries and the public at large.

Government and private establishments should embark on enlightenment programs using radio. television jingles, workshops, seminars, and conferences to educate on the relevancy of projects or programs, revealing its benefits to the community at large; essentially towards improving the people's socioeconomic wellbeing. Also, the tendency to improve control of indiscriminate on-street parking using new technology (CCTV) or making enforcement the sole responsibility of LASTMA excluding the touts as Ikeja could have the potential to increase demand for off-street car parks. In some cases reduction of onstreet car parking is linked with better provision of convenient mass transit for pedestrians. Local planning Authority in the area should specify and enforce the provision of parking space into any structure development be it commercial or residential before approval while the old buildings lining the road in the study location should be renovated to accommodate adequate parking space. This will reduce the current situation of the congestion and else forestall future occurrences. Enforcement Officials should be properly trained and enlightened on the importance of their job with the aim of increasing their level of efficiency in discharging their duties and apprehending violators. For a policy-oriented remark, it's therefore suggested that the implementation off-street compliance with the use to which a land is approved for will tend to mitigate against encroachment and end indiscriminate parking in the study area All hands must be on deck to ensure that violators of land-use and parking rules be severely prosecuted. The strict enforcement of putting violators by the agencies in-charge of guiding lawful and proper parking in the study area will lead to the reduction of spontaneous parking and increase in the efficiency of the transportation routes within and around the CBD. By addressing the abuse of parking facilities, there will be an increase in the efficiency of transportation network as well as ease of accessing the available parking spots provided for motorists. Provision and maintenance of public parking facility is a sole responsibility of the government and its agencies if we are serious in enhancing easy vehicular movement in the CBD. So, it should be handled as such.

\section{References}

Akhuewu. C. (2010): Impacts of on-street parking on commercial activities in Auchi. Unpublished HND Dissertation, Department of Urban and Regional Planning Federal Polytechnic Auchi, Nigeria.

Bekir O. and Surhid P. (1997). Contaminación atmosférica por vehículos automotores: experiencias recogidas en siete centros urbanos de América Latina

Bradley J, 1997. Toward a common parking policy, Transportation Research Record 1564, Transportation Research Board (www.trb.org).

Feeney, and Bernard P. Feeney. (1989). A review of the impact of parking policy measures on travel demand Transport Plan. 229-224.

Fogelson, R. (2002). Downtown: It's Rise and Fall. New Haven. Connecticut: Yale University Press. Sciences (2nd Ed.), London: Thomson Wadsworth.

Jackie, J., and Sculle, K. (2004). Lots of Parking Landuse in a Car Culture. Charlottesville, Virginia: University of Virginia Press.

Kafewo, A (2016). An Assessment of the Methods of Car Parking In Lagos State, Nigeria

Litman, T. (2013). Parking Management, Strategies: Evaluation and Planning. Victoria Transport Policy Institute.

National Population Commission (2006); 2006 Population and Housing Census of the Federal Republic of Nigeria, National and State Population and Housing Tables; Priority Tables (Vol.1). 
Obot, J. D. and Umoh, 2007. Problems and Prospects of Intra-City Transportation in Urban Nigeria; A case Study of Uyo Metropolis in eds, O. B. Ekop; E. Etim and J. D. Obot; physical Development of Urban Nigeria; Emerging Trends and Challenges, Universal Developmental

Ogunsanya A.A. (1986), Traffic congestion in an urban centre: the case of Ilorin Nigeria. Nigerian Geographical Journal, Vol. 27 No. 1\&2, pp. 84-95.

Olorunfemi S. O. (2013) Assessment of On-Street Parking in Lokoja, Nigeria. Unpublished Master Thesis, Department of Urban and Regional Planning, Federal University of Technology Akure, Nigeria.

Osoba, S.B. (2012) Appraisal of parking problems and traffic management measures in central business district in Lagos, Nigeria Journal of Sustainable Development; Vol. 5 (8) 105-115

Oyesiku, O. O. (2002) From Womb to Tomb, 24th Inaugural Lecture, Olabisi Onabanjo University, Ago Iwoye.

Tanimowo, N. B. and Atolagbe, A. M. (2006) Land use and intra-urban travels in Ogbomoso, Nigeria, in eds (J. A. Fadamiro et al,) urban environmental sustainability; interventions and responses; Urban Design Research Team, School of Environmental Technology, Akure.91-99.

Willson, R. (2000) Reading between regulations: parking requirements, planners' perspective, and transit. Journal of Public Transportation. 3 (1) 111-128. 